\title{
Brazilian Presidential Pronouncements in the Pandemic: Effectiveness in Crisis Communication and Rule Properties
}

\author{
Natália Santos Marques ${ }^{1}$ (D) - João Aristides Tomaz de Almeida $^{2}$ (D)
}

Accepted: 24 March 2021 / Published online: 9 August 2021

(C) Association for Behavior Analysis International 2021

\begin{abstract}
This work analyzed the six official statements of the president of Brazil that were broadcast on radio and television during the first 4 months of COVID-19 contamination in the country, regarding the efficacy in communicating the crisis and dimensions of rules. We observed a higher frequency of ineffective excerpts in the statements, especially in the categories "effective fear incitement" and "respect." The categories "speed" and "expression of empathy" showed high efficacy. Additionally, there was a higher recurrence of implicit and inaccurate rules and rules opposing the recommendations of experts. These results indicate that the analyzed statements were ineffective in crisis communication and control of behaviors combating the pandemic in Brazil. The analysis of governmental practices by behavioral science can be useful in the planning of public policies.
\end{abstract}

Keywords Pandemic · COVID-19 - Effective crisis communication · Rule dimensions · Public policies

Governments around the world have been facing, in the last months, a health crisis due to the COVID-19 pandemic, a contagious respiratory disease caused by SARS-CoV-2 (severe acute respiratory syndrome coronavirus 2 ). This disease is characterized by its high transmission potential through infected droplets that are expelled through coughing or sneezing (Singhal, 2020). Although the infected patients vary regarding type and gravity of symptoms, Singhal (2020) indicated that the main symptoms are headache, cough, fever, and breathlessness. The disease more severely affects patients with preexisting chronic diseases and seniors (Guo et al., 2020).

Natália Santos Marques

nataliamarq@yahoo.com.br

1 Universidade Federal do Ceará, Curso de Psicologia, Mestrado Profissional em Psicologia e Políticas Públicas, Fortaleza, Brazil

2 Universidade Federal do Pará, Programa de Pós-Graduação em Teoria e Pesquisa do Comportamento, Belém, Brazil 
Due to the advancement of infections worldwide, the situation has been considered a pandemic by the World Health Organization (WHO) since March 11, 2020. As of March 1, 2021, the WHO has recorded more than 113,000,000 COVID-19 cases in the world and more than 2,500,000 deaths. In Brazil, as of March 1, 2021, more than $10,000,000$ cases of infection with COVID-19 and more than 250,000 deaths have been recorded (WHO, 2021).

In the absence of widely available vaccines, nonpharmacological measures (e.g., social distancing) are still indicated to contain the pandemic (Ferguson et al., 2020; Kissler et al., 2020; Walker et al., 2020). Social distancing has the main purpose of avoiding the spread of infections and the consequent collapse of the health system (Ferguson et al., 2020).

In this sense, the sanitary and scientific authorities agree that social distancing is still an effective method to combat the COVID-19 pandemic. However, as highlighted by Anderson et al. (2020), social-distancing measures should be planned by the government of each nation with attention to the specificities of each context, so that local governments have a crucial role in planning the implementation of measures to fight the pandemic. This statement is in line with what was pointed out by Skinner (1953): The government is the main controlling agency to change behaviors on a large scale, as it is responsible for procedures that strengthen and punish desirable and undesirable behaviors among members of a culture.

As part of the current research efforts involving the COVID-19 pandemic, a team of behavioral scientists with expertise in generating evidence for public policies in Ireland and international organizations gathered data from more than 100 articles, summarizing evidence of behavioral sciences that are useful against the pandemic (Lunn et al., 2020). The authors discussed variables of control and effective interventions for individual and collective behaviors that may reduce the transmission of COVID-19.

According to Lunn et al. (2020), the behaviors of altruistic interest in public welfare and effective crisis communication are the main behavioral drivers of adherence to public-health guidelines during a health crisis. This adherence, as they highlighted, may reduce the pathogen's rate of transmission, decreasing both the total number of infections and the number of cases during the peak of an pandemic (Anderson et al., 2020; Haushofer \& Metcalf, 2020).

Regarding effective crisis communication (the interest of this study), Lunn et al. (2020) gathered valuable information on the communication efficacy of authorities, campaigns, and social media in these situations, pointing out that effective communication informs, motivates, and avoids unnecessary fear incitement at the same time. In short, although there are no definitive crisis-communication practices, these authors pointed out that, according to the analyzed literature, effective crisis communication involves speed, honesty, credibility, empathy, and the promotion of useful individual actions. They still indicated the importance of avoiding the use of specific and extreme cases, avoiding emotional language beyond the expression of empathy, and "sticking dispassionately to numbers," and pointed out the advantages of effective fear incitement (Lunn et al., 2020, p. 21).

Besides the contributions presented in the directly consulted literature, Lunn et al. (2020) presented the guide for crisis communication developed by the U.S. Centers for Disease Control and Prevention (CDC). A result of a previous literature review, this guide presents six general principles for crisis communication: 
(1) Be first: provide information as soon as possible or, if not possible, explain how you are working to get it and when. (2) Be right: tell people what you know when you know it, tell them what you don't know, and tell them if you will know later. (3) Be credible: tell the truth. (4) Express empathy: acknowledge what people are feeling. (5) Promote action: give people relevant things to do. (6) Show respect: involve stakeholders in decision-making processes and try to meet media deadlines. (Lunn et al., 2020, p. 18)

One of the relevant points in the factors of crisis communication is how instructions/rules are communicated to the population. Skinner (1966/1969) described rules as contingencies that specify the consequences of a behavior. On the function of rules, Matos (2001) mentioned that rules are useful for society because it is through them that old members can instruct new ones, transmitting useful cultural practices for the culture's survival. In the current context of the pandemic, rules may facilitate the adherence to measures that aim to fight the pandemic and the consequent survival of the group.

In a taxonomic proposal, Pelaez (2013) categorized rules into five dimensions: (a) explicit versus implicit, (b) accurate versus inaccurate, (c) low complexity versus high complexity, (d) given by others versus self-given, and (e) immediate contingencies versus delayed contingencies. Although this proposal presents a dichotomous model, the author mentioned that the rules can operate on a continuum across the five dimensions. As argued by Pelaez, an explicit rule must identify all the elements of the contingency, because the more explicit the elements expressed in the rule are, the greater their effect (Cepeda Islas et al., 2011).

In turn, an accurate rule describes contingencies that correspond to certain congruent relationships between responses and consequences. Another analyzed dimension of the rules, complexity, refers to the number of dimensions of the preceding stimuli and their relations. According to Albuquerque and Ferreira (2001), the complexity of the rule may affect adherence to it. Herrera et al. (2001) postulated that complex rules consist of a collection of simple rules (Pelaez, 2013). In this respect, rules should be provided from the simplest to the most complex, so that behavior is adjusted to the gradual increase in the complexity of the rule.

Other analyzed dimensions are the source and temporal contingency of the rule. According to Pelaez (2013), the source refers to who gives the rule: either given by others, when the speaker and the listener are different individuals, or self-given, when the speaker and the listener are the same individual. Most of the time, rules are first given by others and then emitted by the speakers themselves (Cepeda Islas et al., 2011). Finally, according to Pelaez, regarding the temporal contingency, a rule may describe immediate or delayed consequences for following or not following it. Thus, it is necessary for rules to adequately describe the delay of the consequence of a behavior.

Analysis of communication (e.g., crisis communication and rule dimensions) is an important topic to evaluate the role of the government in controlling large-scale behaviors. Research has investigated the behavioral effects of communication (Rakos, 1993; Shoemaker \& Reese, 1991). Shoemaker and Reese (1991) pointed out that research involving communication strategies uses as its methodology the examination of the nature of communication's content. They also stated that the content analysis approach is aligned with behavioral traditions that investigate the stimulus 
control relationships produced by the emitted communications. In the same sense, Rakos (1993), when talking about propaganda, mentioned that, from a behavioral point of view, propaganda aims to stimulate the emission of certain behaviors by members of a society. There is evidence available underscoring the relevance of communication when performed by leaders of a nation (Wilson, 2020). In view of the current pandemic context, Wilson (2020) analyzed government actions including communications by New Zealand (led by Prime Minister Jacinda Ardern) about confronting the COVID-19 pandemic. As a result, he pointed out that the goal of promoting a shared purpose (minimize harm to lives and livelihoods) obtained through the actions taken (e.g., lead by expertise, mobilize collective effort, enable coping) resulted in greater adherence of the citizens to government rules. Consequently, this led to New Zealand's success in controlling pandemic cases in the country.

Regarding the control of the COVID-19 pandemic in Brazil, a recent study investigated the relationship between the statements of Brazil's president and the current rates of social distancing (Ajzenman et al., 2020). Through analyses cross-referencing electoral data from 2018 with cell phone location data, the authors identified a strong correlation between the dates of the official statements and the reduction in the indices of social distancing in regions where the president had the largest number of votes in the elections compared to regions where his support was lower. The authors mentioned that the president, in his official and unofficial statements to the media, rejected the risks associated with the COVID-19 pandemic and discouraged social distancing.

The results of Ajzenman et al. (2020) indicated that the presidential communication about the COVID-19 crisis in Brazil may constitute an important determining factor for the population's adherence to social-distancing measures. We emphasize that the work of Ajzenman et al. focused on analyzing possible correlations between the occurrence of verbalizations issued by the president of Brazil and the impacts on the behavior of the population during the pandemic. In a different approach, our work aimed to investigate the properties of presidential discourses and possible relations between the occurrence of verbalizations issued by the presidente of Brazil and the behavior from population. In the face of this indicative, the following questions were goal from this work: First, what are the characteristics of the government's crisis communication in Brazil in terms of its effects on controlling the population's engagement in fighting the pandemic? Second, which dimensions of rules are more recurrently present in the government's communications?

To answer these questions, this work aimed to analyze the official statements of the president of the Federative Republic of Brazil, Jair Bolsonaro, during the COVID-19 pandemic in regard to efficacy of rules and the crisis communication.

\section{Method}

\section{Consulted Material}

We analyzed, in full, all official statements of the president of Brazil that were broadcast on radio and television during the first 4 months of COVID-19 infections in the country, from the first case of infection by the virus on February 26, 2020 (WHO, 2021), to June 26, 2020, totaling six officially transcribed statements: March 6, 2020; 
March 12, 2020; March 24, 2020; March 31, 2020; April 8, 2020; and April 16, 2020 (Palácio do Planalto, 2020).

\section{Procedure}

Initially, we read, in full, all official statements of the president of Brazil. Then, each statement was segmented into representative excerpts based on the subjects covered (e.g., treatment, economics, the health care system, guidelines for the population). The criterion used to define the beginning and end of each excerpt was the introduction and change of the covered topic. Then, the excerpts that resulted from that stage were systematized based on the categories of analysis. The categories of analysis of the president's official statements correspond to the criteria of crisis-communication efficacy reviewed by Lunn et al. (2020) and to the systematization of dimensions of rules presented by Pelaez (2013).

The general principles described by Lunn et al. (2020) classify effective crisis communication in regard to speed, honesty, credibility, effective fear incitement, expression of empathy, promotion of useful individual actions, bias avoidance, and respect. We considered excerpts to be effective when they (a) presented updated information on the crisis and the adopted measures regarding it (speed); (b) presented updates on what was already known and not yet known regarding the crisis (honesty); (c) clarified the extension of uncertainties about current information (credibility); (d) indicated how to act when experiencing fear and/or promoted self-efficacy beliefs (effective fear incitement); (e) expressed empathy; (6) promoted useful actions to combat the pandemic; (g) avoided emotional language, used numbers

in recommendations, and used numbers followed by

uncertainty intervals when announcing predictions and estimations (bias avoidance); and (h) involved the concerned parties in the decision and indicated a commitment to meeting the deadlines announced in the media (respect). We considered excerpts to be ineffective when they related to the categories of analysis but did not meet the criteria of efficacy and/or competed with meeting the criteria. Together, the general principles of the CDC and those pointed out in the review by Lunn et al. were used as categories of analysis of the official statements of the president of Brazil regarding the efficacy of crisis communication. The features of the crisis categories that were used to analyze the presidential pronouncements can be seen in Table 1.

In turn, the rules presented in the statements were analyzed in terms of the following dimensions: clarity (explicit vs. implicit), accuracy (accurate vs. inaccurate), complexity (low complexity vs. high complexity), source (given by others vs. self-given), and temporality (immediate contingencies vs. delayed contingencies; Pelaez, 2013). Thus, we extracted, from the statements, excerpts that were representative of these dimensions of rules. Excerpts that specified the elements of the triple contingency (context, response, and consequence) were considered explicit rules. Excerpts that were coherent between responses and uncertain consequences were considered accurate rules. Excerpts that described few discriminative stimuli for a response were categorized as lowcomplexity rules. We also categorized excerpts that included rules given by others and rules that described temporally close and temporally distant consequences regarding the emission of behavior. The features of rule dimensions that were used to analyze the presidential pronouncements can be seen in Table 2 . 


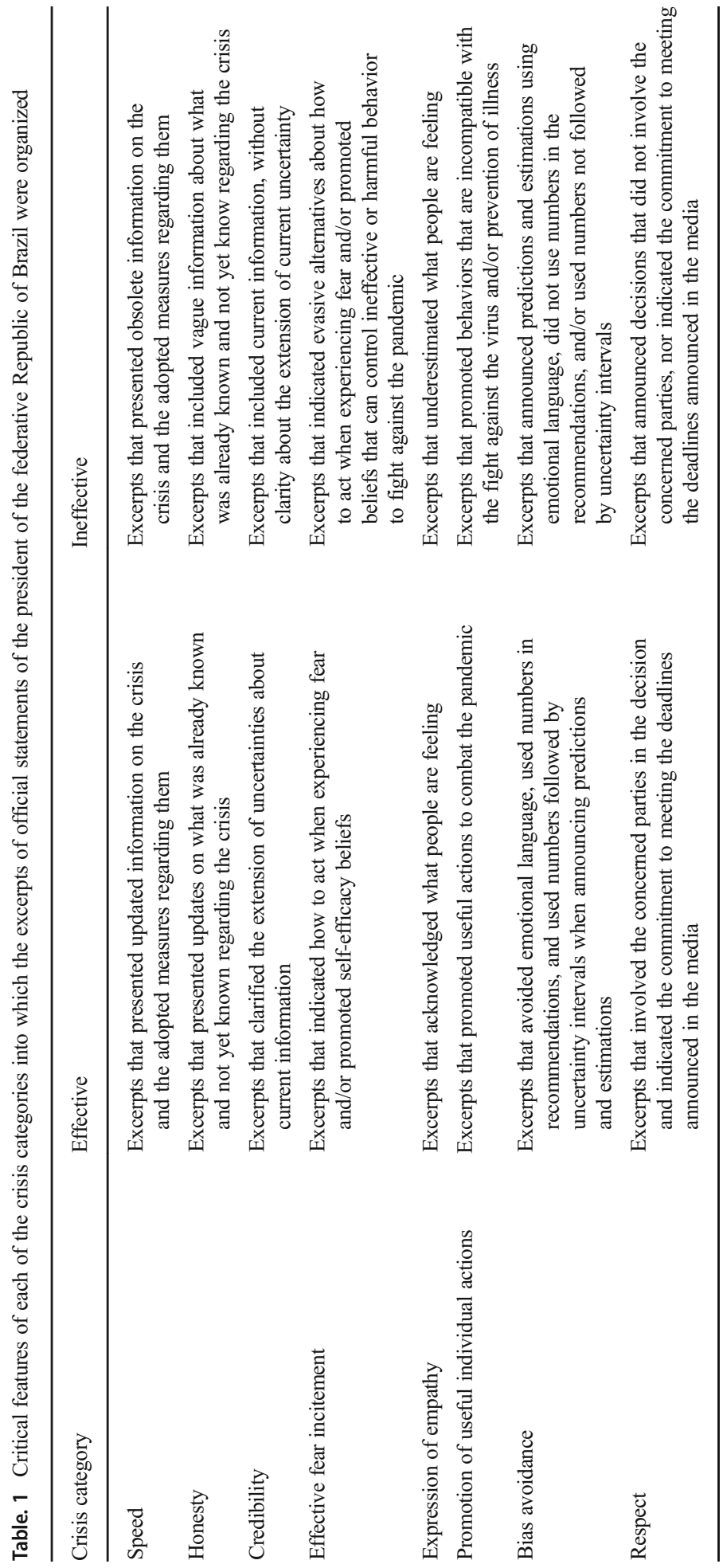


Table. 2 Features of the rule dimensions searched in official statements of the president of the federative Republic of Brazil

\begin{tabular}{|c|c|}
\hline Rule dimension & Feature \\
\hline Explicit & $\begin{array}{l}\text { Excerpts that described rules containing all elements of the } \\
\text { contingency: context, action, and consequence }\end{array}$ \\
\hline Implicit & Excerpts that did not fully describe the elements of the contingency \\
\hline Accurate & $\begin{array}{l}\text { Excerpts that contained rules describing congruent relationships } \\
\text { between responses and consequences }\end{array}$ \\
\hline Inaccurate & $\begin{array}{l}\text { Excerpts that described incongruous relationships between } \\
\text { responses and consequences }\end{array}$ \\
\hline Low complexity & $\begin{array}{l}\text { Excerpts that described rules with the smallest number of } \\
\text { dimensions of antecedent stimuli }\end{array}$ \\
\hline High complexity & $\begin{array}{l}\text { Excerpts that described rules with the greatest number of } \\
\text { dimensions of antecedent stimuli }\end{array}$ \\
\hline Given by others & $\begin{array}{l}\text { Excerpts that contained rules provided by others } \\
\text { (e.g., scientific authorities, medical entities, ministers) }\end{array}$ \\
\hline Self-given & Excerpts that contained rules provided by himself \\
\hline Immediate contingencies & $\begin{array}{l}\text { Excerpts that specified the immediate consequences } \\
\text { of following or not following a rule }\end{array}$ \\
\hline Delayed contingencies & $\begin{array}{l}\text { Excerpts that specified the delayed consequences of following } \\
\text { or not following a rule }\end{array}$ \\
\hline
\end{tabular}

\section{Results and Discussion}

\section{Effective Crisis Communication in Presidential Statements}

The six statements were divided into 63 excerpts, which were analyzed in terms of efficacy and inefficacy in crisis communication. As can be seen in Fig. 1, in general, the official statements of the president were more often based on the rapid presentation of updated information regarding the pandemic. This information is centered on the following subjects: information about the government's actions regarding the pandemic, information regarding hydroxychloroquine, and information regarding the replacement of the minister of health. As an example, in his statement on April 16, 2020, immediately after deciding to remove the then minister of health, Luiz Henrique Mandetta, President Bolsonaro officially informed the population of his decision. Table 3 presents an example of a representative excerpt from each category of analysis (when present).

On offering information, Lunn et al. (2020) highlighted that this can be tricky because, when risk is overestimated in communication, it can increase the economic and social costs of the situation, whereas underestimating the risk may harm efforts for behavioral changes. To this, we add the consideration made by the authors on the importance of campaigns being consistent in order to have an increased probability of being effective. By considering these aspects, it is possible to suppose that demonstrations of a lack of cohesion and consistency in the government's plan to fight the crisis 


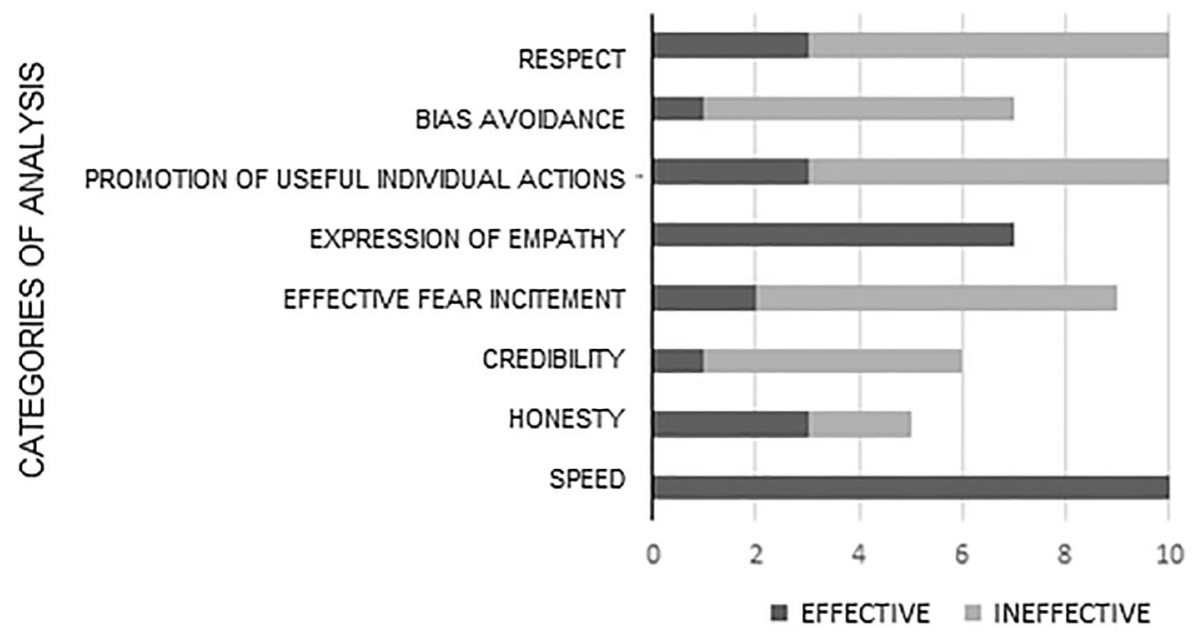

NUMBER OF OCCURRENCES

Fig. 1 Efficacy in communicating the crisis in official statements of the president of the federative Republic of Brazil

(expressed by the replacement of ministers of health) may difficult adherence to health organizations recommendations.

Regarding efficacy, the president's official statements were very effective concerning the speed of information dissemination and the expression of empathy. In the category "expression of empathy," the excerpts referred to the following subjects: preservation of lives, preservation of jobs, solidarity regarding mourning families, and solidarity regarding health providers and/or other active workers, all of which were effective.

Lunn et al. (2020) highlighted evidence that communications that have empathetic appeal (such as personal narratives involving losses or pain in personal relationships) may be more persuasive, causing a more positive impact on the change in behavior (Shen, 2015). Specifically, regarding communication by authorities, the authors found, in the analyzed literature, references to the need for authorities to present empathy in their communications or show that they understand how people feel. Yet, given that, as the authors highlighted, different subgroups may respond differently to crisis communication; communications that are sensitive to the demographic aspects of the group to which they are directed make people feel that society is more prepared to deal with a crisis (Heath et al., 2009).

Regarding the other criteria, there were more ineffective than effective excerpts in the statements, especially about effectively inciting fear, showing respect, promoting useful individual actions, avoiding bias in risk perception, and credibility. In the item "promotion of useful individual actions," the effective excerpts contained direct recommendations to the population about behaviors to prevent the spread of and/or fight against the virus, whereas ineffective excerpts mentioned popular behaviors that are incompatible with fighting and/or preventing the spread of the virus. 
Table. 3 Excerpts of the official statements of the president of the federative Republic of Brazil representing the categories of efficacy in crisis communication

\begin{tabular}{ll} 
Category & Effective excerpt \\
\hline Speed & "A moment ago, I finished a meeting with \\
& minister Mandetta, about 30 minutes, and \\
& we discussed the current situation of the \\
& Ministry, a very productive talk, very \\
& courteous, in which we closed a cycle in \\
the Ministry of Health. He is willing, as I & expected, to participate in a transition as \\
& calm as possible, with the greatest \\
& richness of details that we can offer. And \\
in common agreement, but this is not the & technical term. I will exonerate him from \\
the Ministry in the next hours." (April 16, & 2020)
\end{tabular}

Honesty

"In the past months, a new virus appeared, against which we do not have immunity. The cases began in China, but the virus is already present in all continents. Brazil reinforced its surveillance system in ports, airports and healthcare facilities and was the first country in South America to deal with the disease." (March 6, 2020)

Credibility

Effective fear incitement Expression of
empathy

Promotion of useful individual actions

Bias avoidance
"The virus is a reality, there is still no vaccine or medicine with scientifically proved efficiency, although hydroxychloroquine seems to be very effective." (March 31, 2020)

"Even though the problem may become more severe, there is no reason for panic. Strictly following the recommendation of experts is the best preventive measure." (March 6, 2020)

"Unfortunately we will have losses on this path. I myself have already lost loved ones in the past and know how painful it is. . . . At the same time, we must avoid the destruction of jobs, which is already causing much suffering to Brazilian workers." (March 31, 2020)

"There is also the recommendation of the health authorities for us to avoid great concentrations of people." (March 12, 2020)

"And the government cannot keep this Emergency Aid or other options for a long time. About R \$ 600 billion have already been spent and we may reach $\mathrm{R} \$ 1$ trillion." (April 16, 2020)
Ineffective excerpt "Note: Empty cells represent that the
category did not occur."

"The Brazilian Health System, as in the other countries, has a limit of patients that can receive care. The government is attentive to keeping the evolution of the situation under control." (March 12, 2020)

"There is a higher concern, for obvious reasons, with the elderly." (March 12, 2020)

"The virus has arrived, is being faced by us and soon will be over." (March 24, 2020)

"I believe in God, who will help scientists and researchers of Brazil and the world to cure this disease." (March 24, 2020)

"Note: Empty cells represent that the category did not occur."

"Our life has to go on. Jobs must be kept. The livelihood of the families must be preserved. We must, indeed, go back to normal." (March 24, 2020)

"In my particular case, due to my history as an athlete, if I were infected by the virus, I would not have to worry, would feel nothing or would, if anything, feel it like a little flu or cold, as pointed out by that well-known doctor of that well-known television show.” (March 24, 2020) 
Table. 3 (continued)

\begin{tabular}{lll}
\hline Category & Effective excerpt & Ineffective excerpt \\
\hline Respect & $\begin{array}{l}\text { "With this same spirit, I thank and restate the } \\
\text { importance of cooperation and the } \\
\text { necessary union of everyone in a great } \\
\text { pact for the preservation of life and jobs: } \\
\text { parliament, judiciary, governors, mayors } \\
\text { and society." (31 March 2020) }\end{array}$ & $\begin{array}{l}\text { (31) } \\
\text { everyone. Most of the mass media went in } \\
\text { the wrong direction. They spread exactly } \\
\text { the feeling of fear. . . The perfect } \\
\text { scenario, enhanced by the media, for a } \\
\text { true hysteria to spread across our } \\
\text { country." (March 24, 2020) }\end{array}$ \\
& & \\
\end{tabular}

In the category "effective fear incitement," the effective excerpts included information indicating concrete recommendations for the direct control of the crisis and statements attributing a relationship of causality between the behavior of agents of the society and the fight against the crisis. The ineffective excerpts included statements indicating evasive methods for the direct control of the crisis (e.g., "containing hysteria" or "setting a strategy"), statements underestimating the damage potential of the virus, statements attributing a relationship of causality between the behavior of supernatural beings and the fight against the crisis, and statements attributing a relationship of causality between behaviors of adherence to social distancing and the loss of jobs and access to governmental assistance.

Lunn et al. (2020) highlighted that fear incitement in crisis communication may have a positive influence on behavior (Tannenbaum et al., 2015), especially when this is combined with recommendations about how to respond to this fear and with the promotion of beliefs in self-efficacy (i.e., believing that one's actions make a difference; Peters et al., 2018). Lunn et al. indicated, however, that fear and anger are the main sources of distortions and bias regarding risk perception: Fear tends to increase risk perception, whereas anger may decrease it.

Regarding the category "respect," the excerpts categorized as effective indicated, either directly or indirectly, the participation of different groups of the society and government in fighting the crisis. The excerpts categorized as ineffective mentioned, either directly or indirectly, the existence of opposition regarding the fight against the crisis among different groups of the society or government.

In the category "bias avoidance," only one excerpt was considered effective: information on the amount spent with the government's emergency aid. The excerpts categorized as ineffective concentrated on vague information about prevention suggestions and/or about the capacity of the health system; vague information about the estimation of the number of infected people, number of deaths, and/or duration of the crisis; and the use of specific or extreme cases in communicating about the type and gravity of symptoms.

Lunn et al. (2020) pointed out the existence of strong scientific evidence that suggests that risk perception controls the response behavior to the risk and that such perceptions are very susceptible to distortion and bias (Lerner et al., 2003). To avoid bias in risk perception, the authors indicated the importance of using numbers and uncertainty intervals in communication by authorities. Thus, an example of effective 
governmental communication about the expected number of COVID-19 victims would be "At this stage, our projection is for anything ranging from 3,000 to 22,000, but based on current evidence we think a figure in the region of 12,000 is most likely" (Lunn et al., 2020, p. 20).

In the category "credibility," only one excerpt was categorized as effective. It included information about treatment with clarity about the extension of current uncertainty. Five excerpts were categorized as ineffective. They included information about the treatment, prevention, severity, or spread of the virus and the disease caused by the virus, without clarity about the extension of current uncertainty. According to Lunn et al. (2020), for crisis communications by authorities, it is especially important to be clear about the extension of uncertainty regarding current information, and reminding the population of this uncertainty can be important for credibility.

In the category "honesty," the excerpts categorized as effective included information about the spread of the virus and the lack of immunity against it and risk groups. The excerpts categorized as ineffective included vague information about risk groups and the capacity of the Brazilian health system.

\section{Dimensions of Rules in the Official Statements of the President of the Federative Republic of Brazil}

The six statements were divided into 41 excerpts, which were analyzed in terms of the rule dimensions. Overall, as can be seen in Fig. 2, regarding the dimensions analyzed, the excerpts most recurrently included implicit rules, followed by explicit and inaccurate rules. No significant differences were observed in relation to the other dimensions of rules. Table 4 presents excerpts from each category of analysis (when present).

From the analysis of the presidential statements regarding the dimensions of the rules, we suggest that official statements of the president in the context of the pandemic

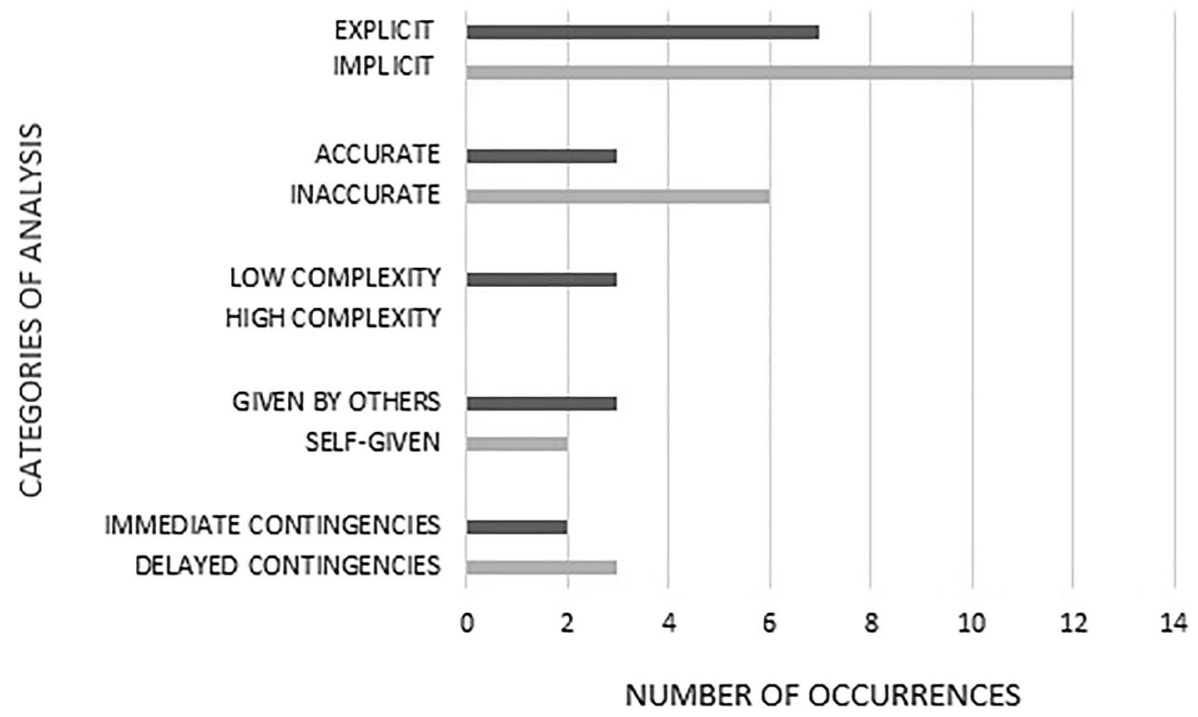

Fig. 2 Dimensions of rules in official statements of the president of the federative Republic of Brazil 
Table. 4 Categorization of the rule dimensions contained in official statements of the president of the federative Republic of Brazil

Rule dimension Excerpts

Explicit

"We must indeed have extreme caution not to transmit the virus to others, especially our beloved parents and grandparents, respecting the guidelines of the Ministry of Health." (March 24, 2020)"Our life has to go on. Jobs must be kept. The livelihood of the families must be preserved. We must, indeed, go back to normal. Some few state and municipal authorities must abandon the concept of "devastated land", transport ban, trade closure and mass confinement." (March 24, 2020)“The humblest cannot stop moving to seek their daily bread." (April 8, 2020)"What I talked about with Dr. Nelson is that, gradually, we have to open the jobs in Brazil." (April 16, 2020)"Together with the virus, an actual job-crushing machine arrived. The humblest people started to feel the problem first. Those cannot stay at home for a long time." (April 16, 2020)"So, it is not what we would like to do, it is what can be done. We cannot harm the ones who need the most. They cannot stay at home for a long time without getting their food." (April 16, 2020)"I know and repeat that life is priceless, but the economy, the jobs, must go back to normal, not as fast as possible, as discussed with Dr. Nelson, but the isolation must be relaxed exactly for us not to suffer more with it (the economic losts)." (April 16, 2020)

Implicit

"Strictly following the recommendation of experts is the best preventive measure." (March 6, 2020)"I call the Brazilian people, especially health providers, for us to work as a unit and overcome together this situation." (March 6, 2020)"We want a people who acting and caring with the public affairs, but we can never put the health of our people at risk." (March 12, 2020)"Our health and that of our family must be preserved. The moment is of unity, serenity and common sense." (March 12,

2020)"The protective measures must be implemented in a rational, responsible and coordinated way." (March 31, 2020)"We must avoid the destruction of jobs, which is already causing much suffering to Brazilian workers." (March 31, 2020)"With this same spirit, I thank and restate the importance of cooperation and the necessary union of everyone in a great pact for the preservation of life and jobs: parliament, judiciary, governors, mayors and society." (March 31, 2020)"I repeat: the side effects of the measures to fight the coronavirus cannot be worse than the disease itself." (March 31, 2020)"I have the responsibility of deciding about the Country's issues in a broad manner, using the team of ministers that I chose to conduct the Nation's fates. Everyone must be in tune with me." (April 8, 2020)"The consequences of the treatment cannot be more harmful than the disease itself." (April 8, 2020)"We must take measures, yes, to avoid the spread of the virus, but by persuasion and with measures that do not affect the freedom and individual security of any citizen." (April 16,2020 )"We are together to protect the life of the Brazilian people, to protect jobs and, also, obviously, seek to bring tranquility and peace to our people." (April 16, 2020)

Accurate

"There is a higher concern, for obvious reasons, with the elderly." (March 12, 2020)"There is also the recommendation of the health authorities for us to avoid great concentrations of people." (March 12, 2020)"The virus is a reality, there is still no vaccine or medicine with scientifically proven efficiency." (March 31, 2020)

Inaccurate

"Even though the problem may become more severe, there is no reason for panic." (March 6, 2020)"It is likely, moreover, that the number of infections will increase in the next days, without, however, any reason to panic." (March 12, 2020)"What is going on in the world has shown that the risk group is that of people older than 60. So why close schools? Fatal cases of healthy people younger than 40 are rare. $90 \%$ will not have any symptoms if become infected." (March 24, 2020)"Without panic or hysteria, as I have been saying from the beginning, we will defeat the virus and will be proud of living in this new Brazil that has everything, yes, everything to become a great nation. We are together, always more united." (March 24, 2020)"I believe in God, who will help scientists and researchers of Brazil and the world to cure this 
Table. 4 (continued)

Rule dimension Excerpts

disease." (March 24, 2020)"I don't rely on these words to deny the importance of the measures to prevent and control the pandemic, but to show that, in the same way, we must think of the most vulnerable." (March 31, 2020)

Low complexity "There is also the recommendation of the health authorities for us to avoid great concentrations of people." (March 12, 2020)“We must indeed have extreme caution not to transmit the virus to others, especially our beloved parents and grandparents, respecting the guidelines of the Ministry of Health." (March 24, 2020)“Our life has to go on. Jobs must be kept." (March 31, 2020)

High complexity "Note: Empty cells represent that the category did not occur."

Given by others

"There is also the recommendation of the health authorities for us to avoid great concentrations of people." (March 12, 2020)“In this respect, Mr. Tedros Adhanom, director-general of the World Health Organization, said he knows that "many people, indeed, have to work every day to get their daily bread' and that 'the governments must take this population into account'. He says yet, 'if we close or limit movement, what will happen to these people who have to work every day and that have to get their daily bread every day?' And he goes on, 'Thus, every country, based on their situation, should answer the question'. The director of the WHO also states that, regarding each measure, 'we have to see what it means for people in the streets.", (March 31, 2020)"The coronavirus issue affects the whole world, and each country has its specificities, as stated by the chief of the WHO." (April 16, 2020)

Self-given

"In my particular case, due to my history as an athlete, if I were infected by the virus, I would not have to worry, would feel nothing or would, if anything, feel it like a little flu or cold, as pointed out by that well-known doctor of that well-known television show." (March 24, 2020)"I am sure that the great majority of the Brazilian people want to go back to work. This has always been my orientation to all ministers while considering the norms of the Ministry of Health.” (April 8, 2020)

Immediate "The virus has arrived, is being faced by us and soon will be over." (March 24, contingencies 2020)"We are concerned with making this return to normality occur as soon as possible." (April 16, 2020)

Delayed contingencies

The coronavirus came and one day it will leave. Unfortunately, we will have losses on this path.” (March 31, 2020)“Unemployment also leads to poverty, hunger, misery and, finally, death itself." (April 8, 2020)“As we have talked to the whole society, formal jobs were being increasingly destroyed. If it comes to such a level which we do not want, other problems will appear." (April 16, 2020)

must contain rules that are explicit, accurate, from low to high complexity, and given by others (e.g., authorities in the field) and that specify the immediate contingencies. In this sense, we mentioned the following hypothetical excerpts that would meet the criterion: (a) explicitness (e.g., "During the pandemic, staying at home is the most effective strategy to avoid infection by the coronavirus"), describing all elements of contingency; (b) accuracy (e.g., "If you do not follow the self-isolation measures, you will likely be infected by COVID-19"), describing congruent relationships between behaviors and consequences; (c) complexity (e.g., "Stay at home"; "Stay at home to fight the virus"; "Staying at home, you save your life and the lives of other people"), so that the behavior is adjusted to the gradual increase in the complexity of the rule; (d) source (e.g., "Scientific authorities have recommended social distancing as the best strategy for our protection"), using rules provided by experts; and (e) time contingency (e.g., "Considering the quick spread of the virus, leaving home at this time may be 
dangerous because many infected people may cause a collapse of the health system"), specifying possible short- and long-term consequences.

Although the aforementioned dimensions are relevant in order to follow a rule, there are still other factors that may affect its effectiveness. Robertson and Pelaez (2018) argued that the probability that listeners (e.g., members of a society) will behave according to rules given by authorities (e.g., governmental agency) depends on three factors: (a) the type/dimensions of the given rule, (b) the context in which the rule is given (e.g., in the context of the pandemic that the country is facing), and (c) the history of the listener with that rule or similar rules. Our work focused on the discussion of the first factor.

Regarding listeners' history with a rule or similar rules, it is important to highlight that this is the first time that a health crisis of such proportions hit Brazil, which demands new cultural practices in a short time interval (e.g., using masks, following social-distancing measures). However, as pointed out by Anderson et al. (2020), countries that presented more effective strategies to fight the COVID-19 pandemic (e.g., Singapore and China) had previously dealt with epidemics (e.g., SARS-CoV in 2002). Finally, it is relevant to discuss the possible impacts of presidential pronouncements on the behavior of the Brazilian population, as can be seen in Figure 3.

As mentioned, on March 11, 2020, the WHO decreed the calamitous situation regarding COVID-19 to be a pandemic. In mid-March 2020, Brazilian state governments began to adopt social-isolation strategies to contain the spread of COVID-19. As a result, in the days leading up to the pronouncement on March 24, 2020, the highest rate of social isolation was recorded thus far in the country $(66.20 \%$ on March 22 , 2020), according to In Loco, a Brazilian technology company that measures socialisolation indexes based on location data. In April 2020, the contagion curve began to grow in Brazil (WHO, 2021). At the same time, there was a decrease in social-isolation measures (In Loco, 2020), as shown in Fig. 3.

We emphasize that the decrease in social isolation is the opposite of what was recommended by scientific authorities, which highlights the role of nonpharmacological strategies (e.g., social distancing) for the control of the COVID19 pandemic until a vaccine would be available on a large scale (Ferguson et al., 2020; Kissler et al., 2020; Walker et al., 2020). As discussed by Lunn et al. (2020), effective crisis communication is one of the main behavioral drivers of adherence to publichealth guidelines during a health crisis. Thus, it is possible that communication in presidential pronouncements was one of the factors that contributed to the decrease in social-isolation rates in Brazil, as Ajzenman et al. (2020) pointed out.

\section{Conclusion}

In the face of high infection and mortality rates worldwide, the COVID-19 pandemic poses a real threat to the survival of cultures. Thus, it demands from controlling agencies, such as the government and scientific community, extensive, urgent, and coordinate measures for the prevention, reduction, and management of the real and potential damage caused by COVID-19, as well as a great adherence of civil society to such control measures. 


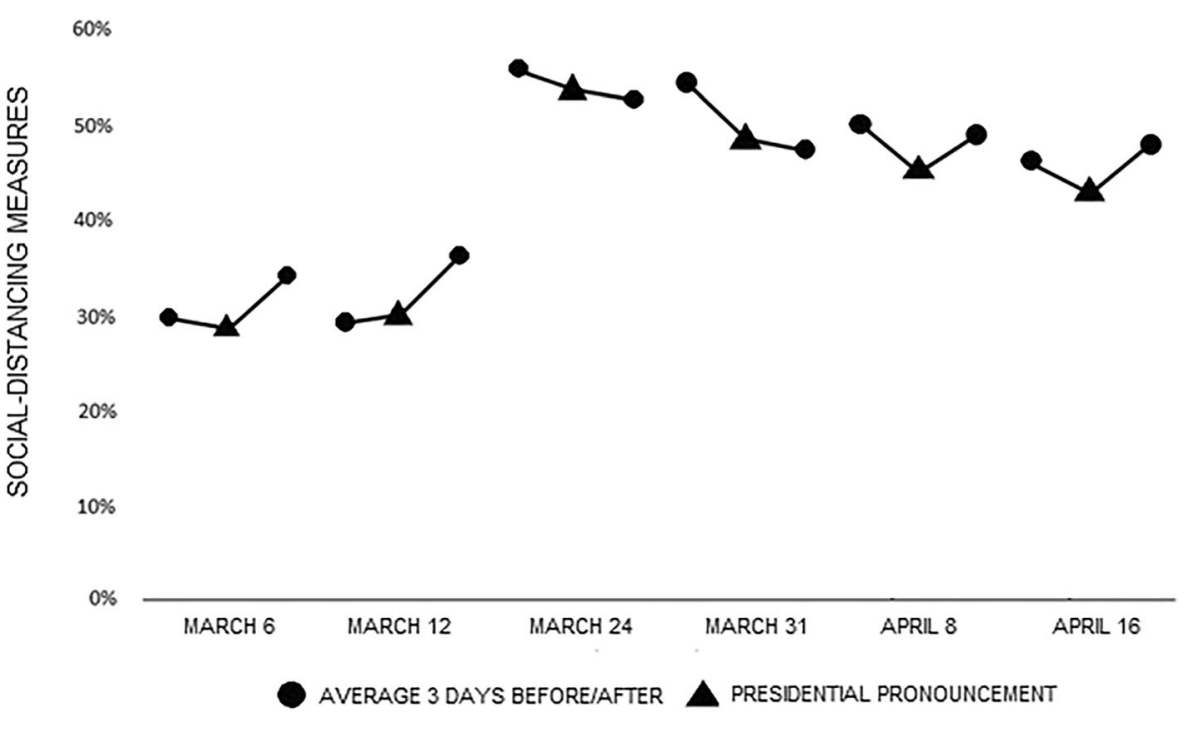

AVERAGE 3 DAYS BEFORE/AFTER PRESIDENTIAL PRONOUNCEMENT

Fig. 3 Measures of social distancing in Brazil from March 3, 2020, to April 19, 2020

An important variable in controlling the effectiveness of the crisis containment measures and the adherence of large populations to such measures, as pointed out by the literature, is the communication by governmental agents (e.g., Ajzenman et al., 2020; Lunn et al., 2020). Our study indicates that, in general, the official statements of the president of Brazil were ineffective in communicating the COVID-19 crisis in Brazil and presented little potential to control the population's behavior to fight the crisis.

Among the possible reasons for the observed effects, we highlight the president's explicitly assumed commitment to "keeping jobs" and "returning to normality" and the underestimation of the damage potential of the virus. The commitment to keeping jobs was presented systematically as direct and indirect recommendations to the population, in the form of recognition, validation, and/or homage to those who left home to work. In a context in which adherence to social distancing is the main measure to fight the COVID-19 pandemic, these assumptions of commitment to keeping jobs can act as a condition that competes with the control of the pandemic. This hypothesis conforms to the analysis of the dimensions of rules, which points out that most of the rules in the statements that were classified as "explicit" encouraged the population to go back to their routines, with such a recommendation going directly against the recommendations for social distancing (Ferguson et al., 2020). We highlight that, in this context of the pandemic, recommendations from the main representative of a governmental agency that compete with or are contrary to social distancing can have harmful effects on the survival of the members of this society, especially considering that we are referring to a country that is the second in the world in the number of deaths (WHO, 2021; data from March, 8, 2021). 
Regarding the underestimation of the virus's damaging potential, this was illustrated by characterizing the disease as a "little flu," characterizing the fear of infection as "panic" and "hysteria," and describing the population affected by the virus in a manner restricted to high-risk groups (older people and those with preexisting diseases). Given the role of governmental communication in the population's adherence to control measures during health crises, it is likely that the underestimation of the damaging potential of the virus, when expressed by governmental agents, would be followed by a reduction of fear regarding the virus and a decrease in the probability of behaviors for controlling the crisis, such as using masks, having good hand hygiene, and, especially, self-isolating, the main target of the statements.

Given this, we do not intend to ignore the importance of measures that aim to preserve formal jobs in a country but to point out the conflict between measures to control the pandemic and orientations that focus on people keeping or returning to their jobs. Communications focusing on alternative measures to preserve jobs, such as decreased taxes for companies that keep their staff or increased taxes for companies that surpass a certain limit of dismissals.

Regarding the dimensions of rules analyzed in the president's official statements, we mostly found implicit and inaccurate rules, categories that are indicated as having little effect on the listener's behavior (Pelaez, 2013; Robertson \& Pelaez, 2018). We suggest that official statements of the president in the context of the pandemic must contain rules that are explicit, accurate, from low to high complexity, and given by others (e.g., authorities in the field) and that specify the immediate contingencies.

Future research should include interrater reliability checks of both the content extracted from the pronouncements and the categorization of the content. ${ }^{1}$ In addition, statements from other sources besides those that were broadcast on radio and television could be analyzed (e.g., newspaper and interviews). Finally, future research could analyze the impact of presidential pronouncements (regarding the efficacy of crisis communication and dimensions of rules) on the adherence of the population to the health recommendations.

As discussed by Rakos (1993), behavioral content analyses would be useful to articulate the specific behavioral processes involved in social phenomena. In one sense, the content analysis presented here details the role of the government in controlling large-scale behaviors to fight the pandemic. Regarding the role of government leaders in the proposition of strategies aimed at controlling the spread of COVID-19, Wilson (2020) mentioned that the New Zealand with an estimated population of 4,800,000 inhabitants had 1,476 cases and 19 deaths (from the first case on February 28, 2020, to April 30, 2020). If we compare deaths due to COVID-19 in New Zealand and Brazil (approximately 210,000,000 inhabitants, 42 times the population size of New Zealand), in the same 63 days since the first confirmed case in the each country, Brazil counted 5,071 deaths (the number of deaths is 266 times higher than in New Zealand), highlighting the importance of government actions to outline strategies to combat the pandemic and the consequent protection of the population.

\footnotetext{
${ }^{1}$ Given the urgency of the scientific analyses that can contribute to the fight against the COVID-19 pandemic, we chose not to include interrater reliability checks. We emphasize that the present analysis followed methodological stages of elaboration, obeying due care in the execution of the work. We also emphasize that the analyzed contents (pronouncements of the president of Brazil) are publicly accessible, allowing for extensive discussion by behavioral scientists interested in content analysis.
} 
Finally, the consideration of functional alternatives to the government's practices, with attention to the relations of control between these practices and the social problem in question, illustrates the potential of applying behavioral techniques, such as functional analysis, in planning, evaluating, and implementing public policies. This contribution becomes especially relevant in conditions in which such practices may have direct effects on the survival of individuals (Dittrich \& Abib, 2004; Melo et al., 2015).

Author Note This work was partially financed by the doctorate scholarship awarded to João Aristides Tomaz de Almeida by Conselho Nacional de Desenvolvimento Científico e Tecnológico.

\section{Declaration}

Conflict of interest On behalf of all authors, Natália Santos Marques states that there is no conflict of interest.

\section{References}

Ajzenman, N., Cavalcanti, T., \& Da Mata, D. (2020). More than words: Leaders' speech and risky behavior during a pandemic. Institute of Labor Economics. https://doi.org/10.2139/ssrn.3582908

Albuquerque, L. C. D., \& Ferreira, K. V. D. (2001). Efeitos de regras com diferentes extensões sobre o comportamento humano [Effects of rules with different extensions on human behavior]. Psicologia: reflexão e crítica, 14(1), 143-155. https://doi.org/10.1590/S0102-79722001000100012.

Anderson, R. M., Heesterbeek, H., Klinkenberg, D., \& Hollingsworth, T. D. (2020). How will country-based mitigation measures influence the course of the COVID-19 epidemic? The Lancet, 395(10228), 931-934. https://doi.org/10.25561/77735.

Cepeda-Islas, M.L., Moreno-Rodríguez, D., Hickman-Rodríguez, A.-H., \& R., \& Plancarte, C. (2011). Task domain and verbal descriptions in the development of general rules of performance. Mexican Journal of Behavior Analysis, 37(2), 117-138. https://doi.org/10.5514/rmac.v37.i2.26143.

Dittrich, A., \& Abib, J. A. D. (2004). O sistema ético skinneriano e conseqüências para a prática dos analistas do comportamento [The Skinner's ethical system and consequences for the practice of behavior analysts]. Psicologia: reflexão e crítica, 17(3), 427-433. https://doi.org/10.1590/S0102-79722004000300014.

Ferguson, N. M., Laydon, D., Gilani, G. N., Imai N., Ainslie K., Baguelin M., et al. (2020). Impact of nonpharmaceutical interventions (NPIs) to reduce COVID-19 mortality and healthcare demand (Vol. 9). Imperial College COVID-19 Response Team. https://doi.org/10.25561/77482

Guo, Y. R., Cao, Q. D., Hong, Z. S., Tan, Y. Y., Chen, S. D., Jin, H. J., et al. (2020). The origin, transmission and clinical therapies on coronavirus disease 2019 (COVID-19) outbreak-An update on the status. Military Medical Research, 7(1). https://doi.org/10.1186/s40779-020-00240-0

Haushofer, J., \& Metcalf, J. C. E. (2020). Combining behavioral economics and infectious disease epidemiology to mitigate the COVID-19 outbreak [Working paper]. Princeton University. https:/www.princeton. edu/haushofer/publications/Haushofer_Metcalf_Corona_2020-03-06.pdf

Heath, R. L., Lee, J., \& Ni, L. (2009). Crisis and risk approaches to emergency management planning and communication: The role of similarity and sensitivity. Journal of Public Relations Research, 21(2), 123141. https://doi.org/10.1080/10627260802557415.

Herrera, G., Pelaez, M., Reyes, G., Figueroa, S., \& Salas, M. W. (2001). Rule following as a function of psychological development and language comprehension (Seguimiento de reglas en función del lenguaje). Mexican Journal of Behavior Analysis, 27, 403-429. https://doi.org/10.5514/rmac.v27.i3. 23584

In Loco. (2020). Mapa brasileiro da COVID-19. Índice de isolamento social [COVID-19 Brazilian map. Social isolation index]. https://mapabrasileirodacovid.inloco.com.br/pt/ (Accessed in June, 13, 2020)

Kissler, S. M., Tedijanto, C., Goldstein, E., Grad, Y. H., \& Lipsitch, M. (2020). Projecting the transmission dynamics of SARS-CoV-2 through the postpandemic period. Science, 368(6493), 860-868. https://doi. org/10.1126/science.abb5793 
Lerner, J. S., Gonzalez, R. M., Small, D. A., \& Fischhoff, B. (2003). Effects of fear and anger on perceived risks of terrorism: A national field experiment. Psychological Science, 14(2), 144-150. https://doi.org/10. 1111/1467-9280.01433.

Lunn, P. D., Belton, C. A., Lavin, C., McGowan, F. P., Timmons, S., \& Robertson, D. A. (2020). Using behavioral science to help fight the coronavirus. Journal of Behavioral Public Administration, 3(1). https://doi.org/10.30636/jbpa.31.147.

Matos, M. A. (2001). Comportamento governado por regras [Rule-governed behavior]. Revista brasileira de terapia comportamental e cognitiva, 3(2), 51-66.

Melo, C. M., Castro, M. S. L. B., \& de Rose, J. C. (2015). Some relations between culture, ethics and technology in BF Skinner. Behavior and Social Issues, 24(1), 39-55. https://doi.org/10.5210/bsi.v24i0. 4796.

Palácio do Planalto. (2020). Pronunciamentos do Presidente da República [Statements of the President of the Republic]. https://www.gov.br/planalto/pt-br/acompanhe-o-planalto/pronunciamentos/pronunciamentosdo-presidente-da-republica. (Accessed in June, 13, 2020)

Pelaez, M. (2013). Dimensions of rules and their correspondence to rule-governed behavior. European Journal of Behavior Analysis, 14(2), 259-270. https://oi.org/10.1080/15021149.2013.11434459.

Peters, G. J. Y., Ruiter, R. A., Ten Hoor, G. A., Kessels, L. T., \& Kok, G. (2018). Towards consensus on fear appeals: A rejoinder to the commentaries on Kok, Peters, Kessels, Ten Hoor, and Ruiter (2018). Health Psychology Review, 12(2), 151-156. https://doi.org/10.1080/17437199.2018.1454846.

Rakos, R. F. (1993). Propaganda as stimulus control: The case of the Iraqi invasion of Kuwait. Behavior and Social Issues, 3, 35-62. https://doi.org/10.5210/bsi.v3i1.198.

Robertson, D. L., \& Pelaez, M. (2018). Rules, rule-governed behavior, and organizational change in a large metropolitan research university. Behavioral Development, 23(1), 1-13. https://doi.org/10.1037/ bdb0000066.

Shen, L. (2015). Targeting smokers with empathy appeal antismoking public service announcements: A field experiment. Journal of Health Communication, 20(5), 573-580. https://doi.org/10.1080/10810730.2015. 1012236.

Shoemaker, P. J., \& Reese, S. D. (1991). Mediating the message: Theories of influences on mass media content. Longman.

Singhal, T. (2020). A review of coronavirus disease-2019 (COVID-19). The Indian Journal of Pediatrics, 87, 281-286. https://doi.org/10.1007/s12098-020-03263-6.

Skinner, B. F. (1953). Science and human behavior. Simon \& Schuster.

Skinner, B. F. (1969). An operant analysis of problem solving. Em B. F. Skinner, Contingencies of reinforcement: A theoretical analysis (pp. 133-171). Appleton-Century-Crofts. [Originally published in 1966]

Tannenbaum, M. B., Hepler, J., Zimmerman, R. S., Saul, L., Jacobs, S., Wilson, K., \& Albarracín, D. (2015). Appealing to fear: A meta-analysis of fear appeal effectiveness and theories. Psychological Bulletin, 141(6), 1178-1204. https://doi.org/10.1037/a0039729.

Walker, P. G. T., Whittaker, C., Watson, O., Baguelin, M., Ainslie, K. E. C., Bhatia, S., et al. (2020). The global impact of COVID-19 and strategies for mitigation and suppression (Vol. 12). Imperial College COVID-19 Response Team. https://doi.org/10.25561/77735

Wilson, S. (2020). Pandemic leadership: lessons from New Zealand's approach to COVID-19. Leadership, 16(3), 279-293. https://doi.org/10.1177/1742715020929151.

World Health Organization. (WHO, 2021). Coronavirus disease (Covid-2019) weekly epidemiological update and weekly operational update. https://www.who.int/emergencies/diseases/novel-coronavirus-2019/ situation-reports. Acessed 8 Mar 2021 